Historic, Archive Document

Do not assume content reflects current scientific knowledge, policies, or practices. 


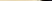




\section{SPECIAL CATALOGUE of STRAWBERRY PLANTS}

\section{FROM \\ The Lafayette Nurseries}

\section{West Lafayette, Indiana}

We offer only the choicest and best stock of fruit and Ornamental Trees, Evergreens, Shrubs, Roses,

Grapevines, etc. Catalogue mailed free. 


\section{Shipping Strawberry Plants by Parcel Post}

Your order for Strawberry plants may be shipped by Parcel Post and, when shipped in this way, it will come to you as your other mail does. If you are living on a rural route some distance from town, your plants will be delivered at your door. We ship hundreds of orders by Parcel Post and our customers find it satisfactory, and this means of shipping plants is becoming very popular. It is our opinion that customers find Parcel Post cheaper than Express when shipments are made into the First, Second, or Third Zones.

WE PREPAY POSTAGE on all orders not exceeding 300 plants. We advise orders for more than 300 plants be sent by Express. But at the request of the purchaser larger orders may be sent by parcel post, purchaser remitting postage extra. We do not prepay express shipments.

\section{"I AM VERY MUCH PLEASED WITH THE TREES AND PLANTS I BOUGHT OF YOUR NURSERY"}

Many of our customers have written us letters like that. And a lot more have shown their satisfaction by sending us repeat orders. Over 42 per cent of our business in 1919-20 came from our old customers. Add to that the new orders that came from their recommending us to their friends and you can readily understand why we are so particular to send out nothing but first-class nursery stock and to supply reliable information on how to take care of it.

We appreciate that "a satisfied customer is the best advertisement." We are particularly dependent upon the good will of our customers for our continued success, because we have no agents but sell direct-from-nursery only.

Most people like our methods of doing business. They like to know that they are getting as good terms and prices as the other fellow. They realize the advantages of buying from a responsible concern that is evidently interested in their success-that is always ready to supply needed information and to promptly adjust any mistakes.

Remember that when you order your trees and plants from our catalogue you are not paying agent's commission, traveling expenses, hotel and livery bills, etc., etc., in addition to a fair price for the goods.

There is almost a famine throughout the world. Revolution and anarchy are prevailing in parts of Europe because people are starving to death.

Food will still be shipped to Europe, and we must produce more food. Every basket of fruit out of our gardens increases the food supply of the world. It releases pressure somewnere else, and at the same time it helps to reduce the high cost of living. 


\section{Our Exceptional Fine Location}

OFFICE and packing grounds on the Electric Street R. R., immediately west of and adjoining the U. S. Experiment grounds and Purdue University. Our shipping facilities are unexcelled, as we have the Big Four branch of the New York Central lines; the Wabash railroad and the Monon and Lake Erie \& Western railroads, besides two interurban lines, also, the American, United States and Wells-Fargo Express companies, insuring speedy and prompt delivery of stock.

\section{ADVANTAGES OF LOCATION}

LOCATED as we are, adjoining the U. S. EXPERIMENT STATION, where hundreds of varieties of fruits are tested each year by the U. S. Department of Horticulture, in their experimental tracts-our facilities for obtaining the very best and latest improved varieties, adapted to our soil and climate, are unequalled by any establishment in this country. Our customers, unfamiliar with the different varieties of fruits will do well to leave the selection of varieties largely to us, as we can assure them the benefit of our many years of experience in addition to the information gained by careful study of the many varieties thoroughly and scientifically tested every year by the department of horticulture at the U. S. EXPERIMENT STATION at PURDUE UNIVERSITY.

\section{OUR GUARANTEE}

Our plants are fresh dug at time of shipment, from new beds, carefully trimmed, re-sorted to best grade only, and tied in bunches. Good count and true to name, and are put up with finest moss in packages, if to go by mail, or in market baskets lined with moss and oiled paper or light, ventilated crates, to carry safely by express at lowest rates.

It is our intention that every variety offered and priced in this circular will reach you in good growing condition and prove to be precisely as described. All plants shipped by us are true to name, healthy, and carefully packed.

You take no risk in sending us your order, for we absolutely guarantee you satisfaction. We make good any order which proves unsatisfactory.

Certificate of Inspection is attached to every shipment.

\section{TERMS}

CASH with order, but orders will be booked to hold plants if part payment is enclosed, the balance to be sent before shipment. Remittances may be sent by postoffice or express money order, bank draft or CHECK, or small sums in one or two cent stamps. A CHECK IS OFTEN MORE CONVENIENT FOR OUR CUSTOMERS and is equally acceptable with us.

\section{PLANTS BY PARCEL POST}

We would strongly urge the advantage of our Parcel Post system for handling Strawberry plants in small quantities-300 plants or less.

WE PREPAY postage on all parcel post shipments, and your plants are laid down at your door all ready to plant-guaranteed to reach you in perfect condition. Simply write out your check and mail it to us and we will see that you are more than pleased.

\section{ORDERS exceeding 300 plants should go by express.}

OUR PRICES-We think our prices as low as any reliable grower can offer the same grade of goods. Some may offer lower prices, but the best plants are always the cheapest in the end. Try ours.

OUR STOCK is equal to any grown, and you may always rely on getting it fresh and full of life, and as our soil is especially adapted to the growing of plants, we send out as fine roots as any on the market. 
Many new customers come to us each season because of the good things they have heard about our stock from satisfied customers and the endorsements of demonstrators and instructors in Agricultural Colleges. To all customers this year we say you can depend on our giving you the same kind of good stock and service. When you have tried our nursery stock you will be just as well satisfied as our regular customers. Every order you place with us will mean greater satisfaction and confidence. We offer trees and plants direct from our nursery to you and save you all the in-between profits. We are able to give you the best trees and plants, best service, best satisfaction, by selling direct to you. Our principles of service to our customers, integrity of grading, accuracy of counts, perfection in packing, and a super-guarantee devoid of strings or catch words should appeal to you.

\section{IMPORTANT}

ORDER EARLY. Transportation conditions are not the best now, but if you send your order to us early you need not worry about late deliveries. We will make prompt shipment and guarantee arrival in perfect condition. Do your part and we will do ours.

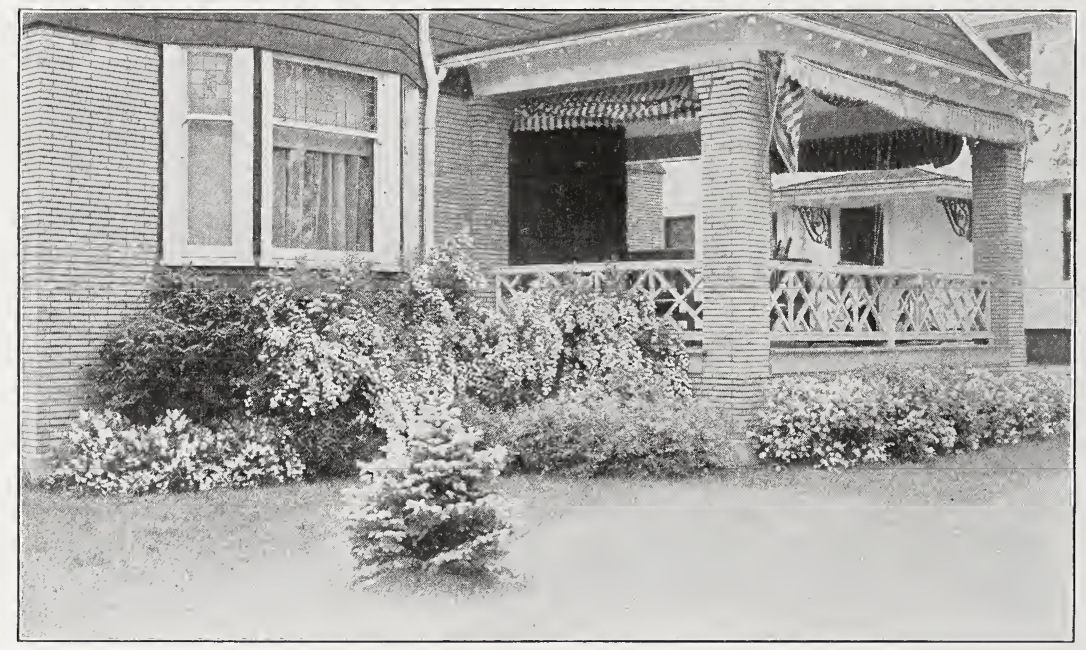

\section{LANDSCAPE GARDENING}

Our Landscape Department is prepared to furnish attractive planting plans for small city lots up to large private grounds, public parks, factory grounds, cemeteries, summer resorts, schools, colleges, libraries, hospital grounds, etc. Our landscape architect is one of the leading men in his profession in the country. In our work we use hardy, flowering shrubs, herbaceous plants and vines, ornamental and shade trees; aiming to give, not alone foliage and flowers from spring to autumn, but pleasing bark and berry effects during the winter months. This work is not expensive, costs but little, and pleases so much, besides enhancing the value of the property. If interested, write for information early as possible as we have many appointments ahead.

\section{FRUIT AND ORNAMENTAL TREES}

We offer also a full and complete stock of Apple, Pear, Cherry and other fruit trees, Grapevines, Shrubs, Roses, Climbing Vines, Evergreens, Shade and Ornamental and Nut Bearing Trees. Also Raspberry and Blackberry, Currant and Gooseberry Bushes. A large and beautifully illustrated descriptive catalogue will be sent free on application.

AT PRICES quoted in this list 500 plants will be supplied at the 1,000 rate. We do not offer less than 25 plants of one variety in strawberries and raspberries and blackberries. They are all tied in bunches of this number and we do not break bunches as too much time is required to break bunches and recount. 


\section{Mighty Interesting Facts About Strawberries}

Don't imagine for a moment that any fixed rules must be followed to get plenty of good Strawberries; just resolve to have a good big Strawberry bed. Take any land available, enrich it with any plant-food you can get, put in the plants in straight or crooked rows, as far apart or as close as you like, cultivate freely through the season with any tools at hand. Just shake up the soil, keep out all grass and weeds and see the Strawberry plants grow; and even if you get lazy toward midsummer and do not hoe and weed any more, if the plants have obtained a good start, why, no matter if the grass and weeds do make the bed look unsightly by fall, you may be sure there will be a lot of Strawberries there next June, and your family will enjoy them so well, and want more, that you will take better care of the next bed, and so get still better results.

The first right thing to be done is to plant a Strawberry bed, then care for it any way you like; you are bound to improve in method and results as the years go by.

What to plant is a local question, to be answered only by one's taste and soil conditions; there is no one best Strawberry for all soils and purposes. Some of the big, luscious varieties that thrive so well on heavy clay soils fail almost entirely on sandy loams, where some of the great quart-yielding market varieties are at their besi.

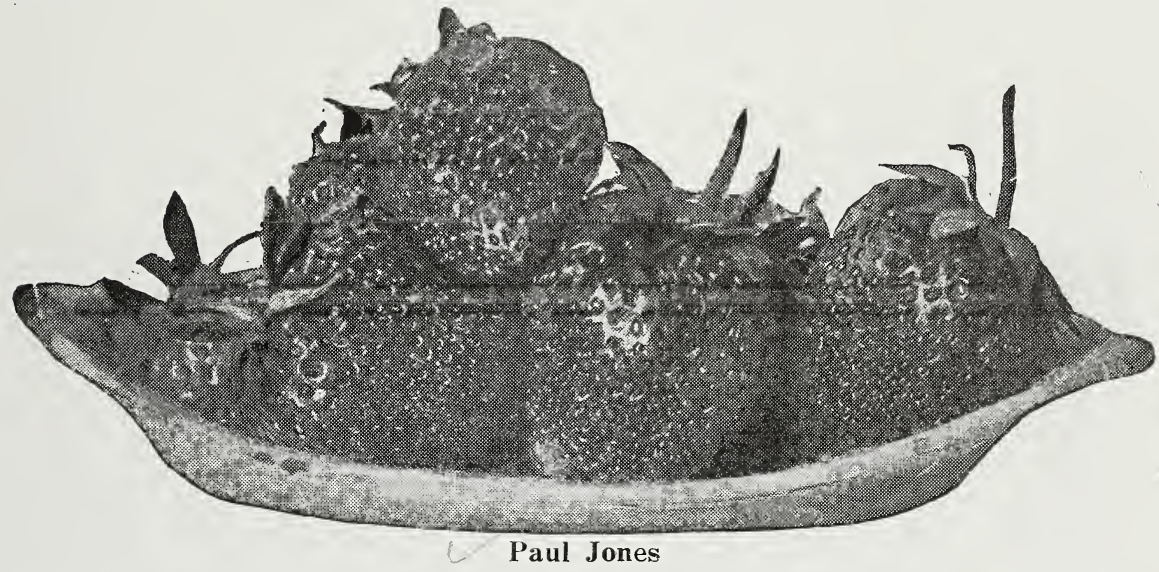

Having grown nearly every variety that has been known within the past forty years, and discarded the inferior ones from year to year, we feel confident there are none better in America today than those offered in this little Catalogue. It represents the boiled-down experience of a lifetime, and ought to be of great value to those who have not had the benefit of long years of actual experience. It is worth a whole lot of money to be able to buy your plants and trees of a nurseryman who has extensive fruiting fields and orchards, and who can furnish plants, trees and information of actual fruiting experience.

Early spring is the best time to put out plants; they are cheapest then and are more sure to live in transplanting, and they need one year's growth in the new bed to fit them for greatest fruitfulness. Don't be fooled into summer planting if you want highest success; plant Strawberries in spring.

There is a whole lot of fake talk about so-called "pedigree plants," "plant selection," etc.; but, having tried them all, we are frank to say that any plants that are pure and true to name have brought just as good results as the so-called pedigree plants. The "pedigree" needs to be in the man or woman back of the job. Get our plants and follow the general instructions here given, improve on them all you can, don't worry about "pedigree," and you should have as fine Strawberries as any on earth. 


\section{Everbearing Strawberries}

We have been growing the Everbearing Strawberries for the past six seasons, and the past season has proven beyond all doubt that they are with us to stay. Nearly every one of our customers ordered them last season, and we have received reports from our customers in all parts of the country telling us about the complete satisfaction they are giving.

Although we have greatly increased our acreage of the Everbearing varieties each season, we have never been able to supply the demand. They are being grown more extensively each season, as the growers become better acquainted with the wonderful possibilities of these varieties.

PROGRESSIVE (Per.)-This variety is head, neck and shoulders ahead of any other variety of fall-bearing in matter of productiveness. In appearance the fruit closely resembles the Dunlap. It is similar to Dunlap in quantity and cannot be surpassed for flavor.

The plants are of a healthy green color, deep rooted and medium in size. We do not hesitate to urge you to grow Progressive, and if grown properly for the fall crop, you can make more money from one acre, than from any other variety, either stand or fall-bearing.

This is the only really "fall-bearing" variety, as this sort will bear a heavy crop during the fall months on plants set the previous April.

Other varieties will bear a few berries the first fall, but you must wait until the following year for a crop, and then if you let plants bear the June crop, as they will unless disbudded, they are so exhausted that the fall crop is much smaller than the Progressive gives the first season. We do not hesitate to urge all to try these berries, for we know you will be pleased. Some of our friends seem to be afraid that they will not succeed with them, but anyone that can grow the June sorts successfully can grow these. The only difference in culture is that you must keep the bloom picked off until about the middle of July for best results.

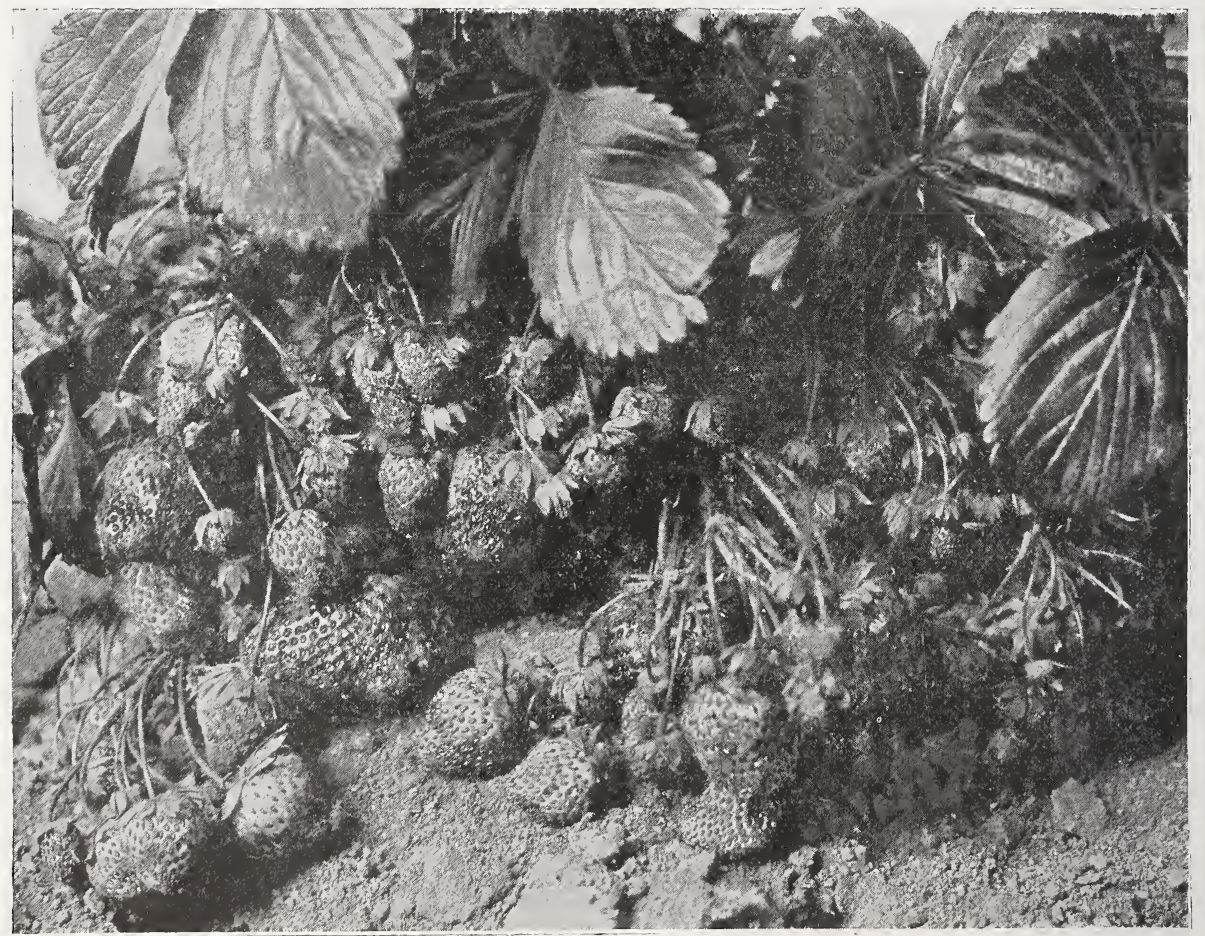

Progressive Everbearing 


\section{General List of Varieties}

We are listing only the varieties that have proven their value. Owing to the high cost of labor, etc., it is essential that you grow varieties that you can rely upon to produce a good crop of berries. Your success depends largely on the plants you buy. They must come from soil that produces strong, healthy and productive plants. We have this kind, and want your order. You will be assured of getting some of the finest plants it is possible to grow.

Our variety descriptions are a little shorter than in the past. The facts about them are told honestly and you can rely on them.

Look over our list, select what you want and send your order NOW. The earlier the better, and the more sure you will be of getting what you want.

Varieties are arranged in the order of ripening. All orders for 300 plants or less will be sent by parcel post, prepaid by us at prices named. Orders for a greater number than 300 plants will be sent by express, unless otherwise instructed, purchaser paying the express charges.

Prices of all of the following varieties except where noted: 50 plants for $\$ 1.00$, 100 plants for $\$ 1.50,1,000$ plants for $\$ 12.50,500$ plants or more at the 1,000 rate.

EATON (Perfect) - "The Strawberry Supreme." This most wonderful strawberry was discovered by Mr. A. V. Eaton, a veteran strawberry grower of Lafayette, Indiana, who, having recently retired from his activities, has since removed to Indianapolis.

Mr. Eaton discovered the original plants of this variety in an orchard growing in a bed of wild strawberry plants. He became impressed at once by the wonderful attractiveness of both fruit and foliage and removed some of the most vigorous plants to his garden where he watched them carefully for some time, comparing the qualities of the plants closely with those of the standard varieties growing on his grounds.

After assuring himself that this berry possessed superior qualities, he began fruiting it on a commercial scale, and met with surprising success at the start. He found that the Eaton surpassed all of the standard varieties grown by him, and that immediately upon its appearance on the market a demand for his product was created far greater than he could supply. His sales on the Lafayette market continually exceeded those of other growers by seventy-five cents to one dollar a crate, all dealers buying the Eaton in preference to any other variety offered, and being willing to pay a higher price to get it.

During Mr. Eaton's early observation with this variety he came to the conclusion that it may have been crossed with Sen. Dunlap, for the best berries of each variety are similar, but the likeness stops there, for Eaton is distinct in every way.

The bloom of this plant is staminate, requiring no other pollenizer. The fruit begins ripening with the second early varieties, and continues through a long season, bringing the last berries to perfect maturity, so that it may be classed as a midseason to late variety.

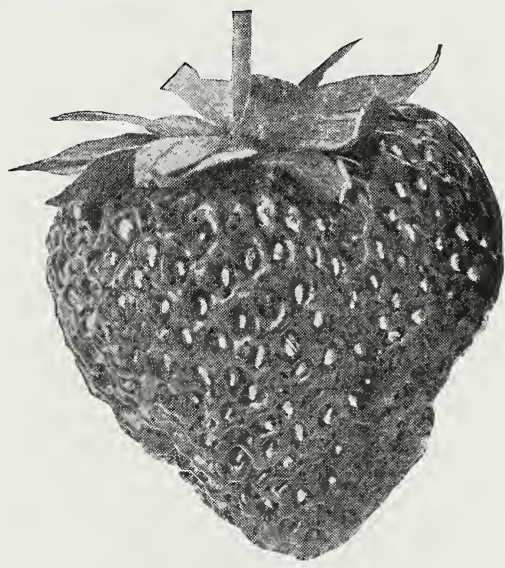

The Eaton

The berries are of a deep red color, which extends to the heart of the fruit, and are of an exceptional size, a perfect cone in form, holding this shape to the last; and have never been known to produce a misshapen berry, nor any with white or green tips.

The flavor of the fruit is all that could be desired. It is of a very firm texture, which, combined with its wonderfully attractive appearance, gives it all of the necessary qualities of a successful market variety.

While we have found the Eaton to possess good canning qualities, and to have a very attractive appearance in the can, still we must recommend Dunlap as its superior in this one respect. 
The plant growth of Eaton we find to be equal to Sen. Dunlap in the number of plants produced, but in size the plants are much larger, some of the leaf stalks measuring eighteen inches, with fruit stems in proportion.

Having offered Eaton to the public for the first time last season, it has not yet become thoroughly disseminated throughout the various sections of the country, and time alone will show us whether it will do as well under other climatic conditions as in this part of the country. This is the only unproven quality of the Eaton, and when this one point is dem- onstrated satisfactorily, nothing can prevent its becoming a universal winner.

The Middle West is the native home of the Eaton, and to all of our customers living in this section, we recommend that you plant Eaton in large quantities without hesitation; while to those living in more distant sections, we advise that you give the variety a more limited trial, planting only from five hundred to a thousand plants.

We have a large stock of Eaton this year, and consequently are offering it at a great reduction in price over that of last year. Price $\$ 1.00$ per $25 ; \$ 2.50$ per $100 ; \$ 20.00$ per 1,000 . (Five hundred or more at the thousand rate.)

\section{Early Varieties}

PREMIER (Per.)-Kellogg's Premier is the best extra early variety ever grown; the greatest money-maker of the early varieties. It has been tested in all parts of the country and everywhere we hear nothing but praise for this wonderful variety. It is a strong, vigorous grower -plant growth being ideal, clean and free from rust from spring till fall. It is a heavy producer of large beautifully formed berries that are bright red clear through to the center. It is delicious in flavor and a splendid shipper and you should plant heavy, whether growing for home use, local market or distant shipping. If Premier has any weak points we have not found them and would advise all those in sections where early strawberries are in demand to include

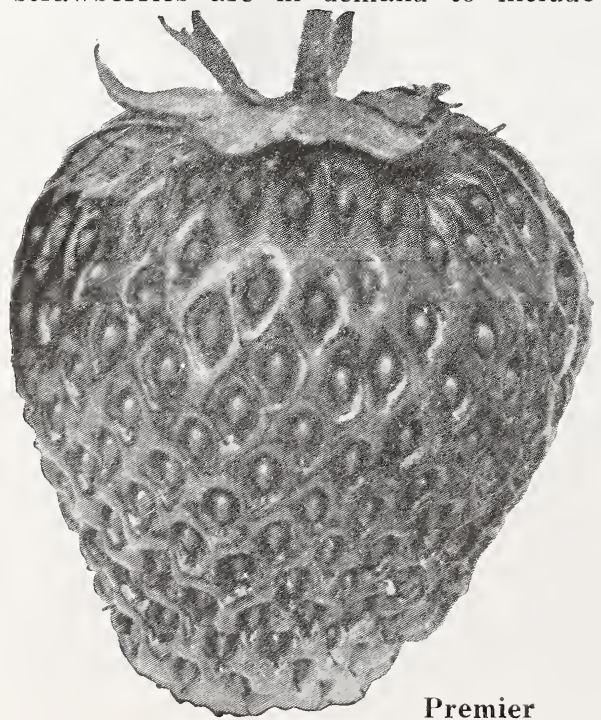

Premier whether setting fifty plants or fifty thousand. We are going to plant more of this variety for fruit next season than any other variety this is what we think of it.

Kellogg's Premier is distinctly in a class by itself; in productiveness it is a wonder. The berries are mammoth in size. Every berry is a show berry, and a prize winner. It is the money-making king of all early varieties. Last year the premier began ripening fully a week earlier than any other variety and continued for four full weeks and the last picking was as good as the first. Another quality in which the Premier excels is that of a Pollenizer for Pistillate sorts, because of its unusual long blooming season. If you believe that you have already seen the greatest early berry, but have not seen the Premier, you still have something worth while to discover in the strawberry world. And if you would grow berries to sell at your own price, no matter how many other berries are on the market, Premier is the variety for you to choose. We would rather pay $\$ 10.00$ for Premier plants than have any other variety at a gift. Price $\$ 1.00$ per $25 ; \$ 2.50$ per $100 ; \$ 20.00$ per 1,000 .

HOWARD NO. 17 (Per.)-While this variety is new to the public it has been grown for years by the originator. It has also been grown on the Experimental Grounds of the Connecticut Agricultural College for 13 years, where it has come in competition with hundreds of other varieties and has been an easy victor over all and it now holds the title as the best variety ever grown there. This variety was originated by Howard \& Son, a firm of fruit growers in Massachusetts some 18 years ago. For some 


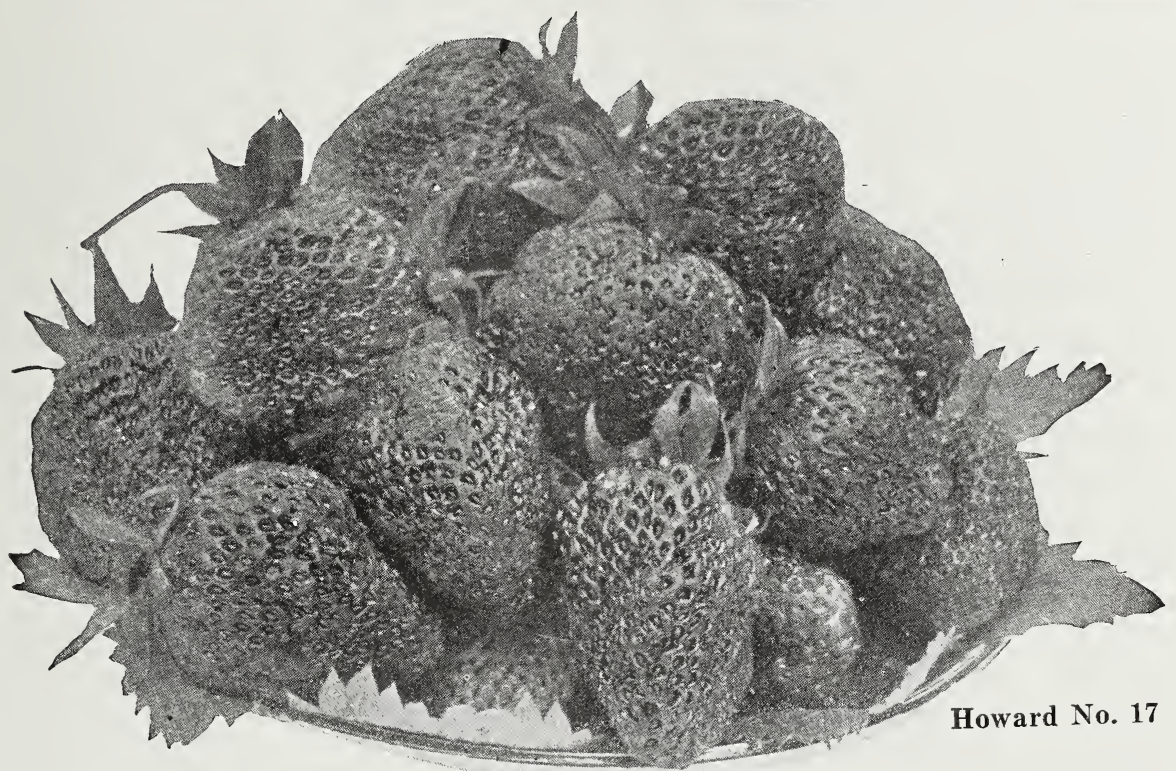

reason or other they have not seen fit to let the public have any of these plants, they evidently thought so much of Howard No. 17 that they preferred to fruit it. Prof. A. T. Stevens, connected with the Massachusetts College first told us about this berry. We wrote the originators but there was absolutely nothing doing. A year later we related our experience to Prof. A. T. Stevens, when he kindly offered to send us a few plants. We have fruited it and it has indeed proven to be a great prize.

The plants of this variety are the healthiest of any we ever saw. The plants are large and rugged and make plenty, but not an excessive amount of

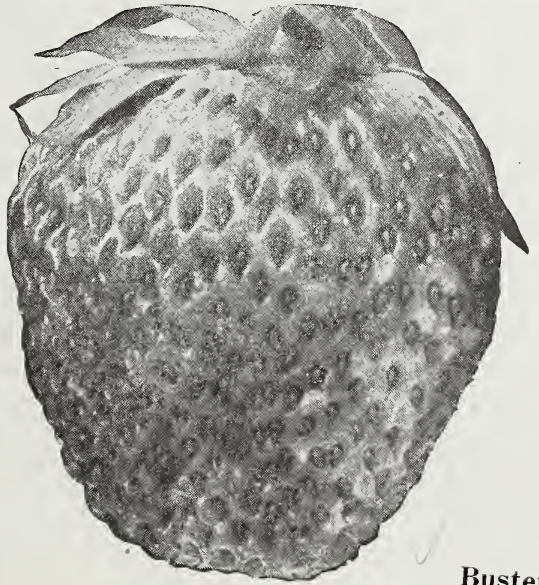

runners. In plant growth they are faultless. The blossoms are large and have plenty of pollen. It is among the earliest of the midseason varieties to ripen. It is

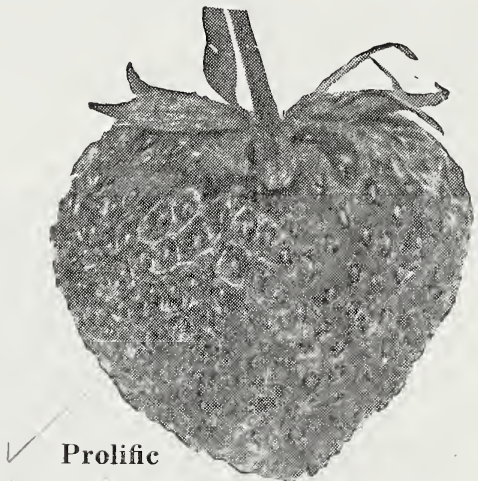

the earliest fancy variety we have ever seen and holds up in size remarkably well. The first berries to ripen are wedge shape, soon becoming conical, berries are firm and carry well when shipped.

Color rich red with a fine gloss. There is no berry that we have ever seen that is more beautiful or of finer quality. The only fancy berry that is a "Business Berry." The Howard No. 17 has all the good qualities of the others combined with heavy production. In size it is among the largest grown, averaging larger than either Gandy or Chesapeake. The Howard has outclassed every variety we have and outyielded our best variety by one-third. 
We bought our original stock of this variety direct from the introducer, $\mathrm{Mr}$. Chapman. We have never fruited them, but can say that they surely produce a very fine plant. With the evidence we have given which is only a very small portion of that given by the introducer, we do not see how anyone can go wrong in buying a few of this variety. We only have a small stock of these plants. Price: 25 plants for $\$ 1.00 ; 100$ for $\$ 2.50$; 1,000 for $\$ 20.00 ; 500$ at 1,000 rate.

EARLY JERSEY GIANT (Per.) - A very large, medium early berry of the highest quality. It ripens evenly all over and is conical in shape, with pointed tips. The berries have large, green caps which makes the fruit very showy and attractive. Blossoms perfect. Plants large and strong. The berries are firm enough to ship and with its handsome appearance, always commands top prices. It is one of the best medium early fancy berries. Highly recommended by Purdue Experiment Station. Price: $\$ 1.00$ per $25 ; \$ 2.50$ per $100 ; \$ 20.00$ per 1,000 .

MINNESOTA NO 3 (Perfect)-(Experiment Station, St. Anthony Park, Minn.) Originated at Minnesota Fruit Breeding Farm, Excelsior, Minn. It is a cross between Dunlap and Pokamoke; introduced by the Experiment Station about 1914 .
Plants numerous, vigorous, nearly free from leaf-spot, very productive; leaves of medium size, thickness and color, glossy, rugose; ffowers perfect, bloom in early mid-season. Fruit matures medium early; large to medium, dropping in size as the season advances, conic, the base irregular, strongly necked, attractive, glossy, very juicy, firm, pleasantly sprightly; good in quality. Resembles Dunlap in type, of good color and pleasing flavor. Price: $\$ 1.00$ per $25 ; \$ 2.00$ per $100 ; \$ 15.00$ per 1,000 .

ST. LOUIS (Per.)-We needed another good early variety, and this one seems to be just what we are looking for. The plants are large, with tall, bright glossy green foliage, very deep-rooted, and great drought-resisters. It is very productive for an early variety and the fruit is large, roundish conical, bright, glossy red, and of good quality. The fruit-stalks are large and strong and keep the fruit from the ground. It is in great demand on account of its earliness, large size, and productiveness, and it is firm enough for shipment to markets that are not too far distant. Purdue Experiment Station recommends this variety for the home garden.

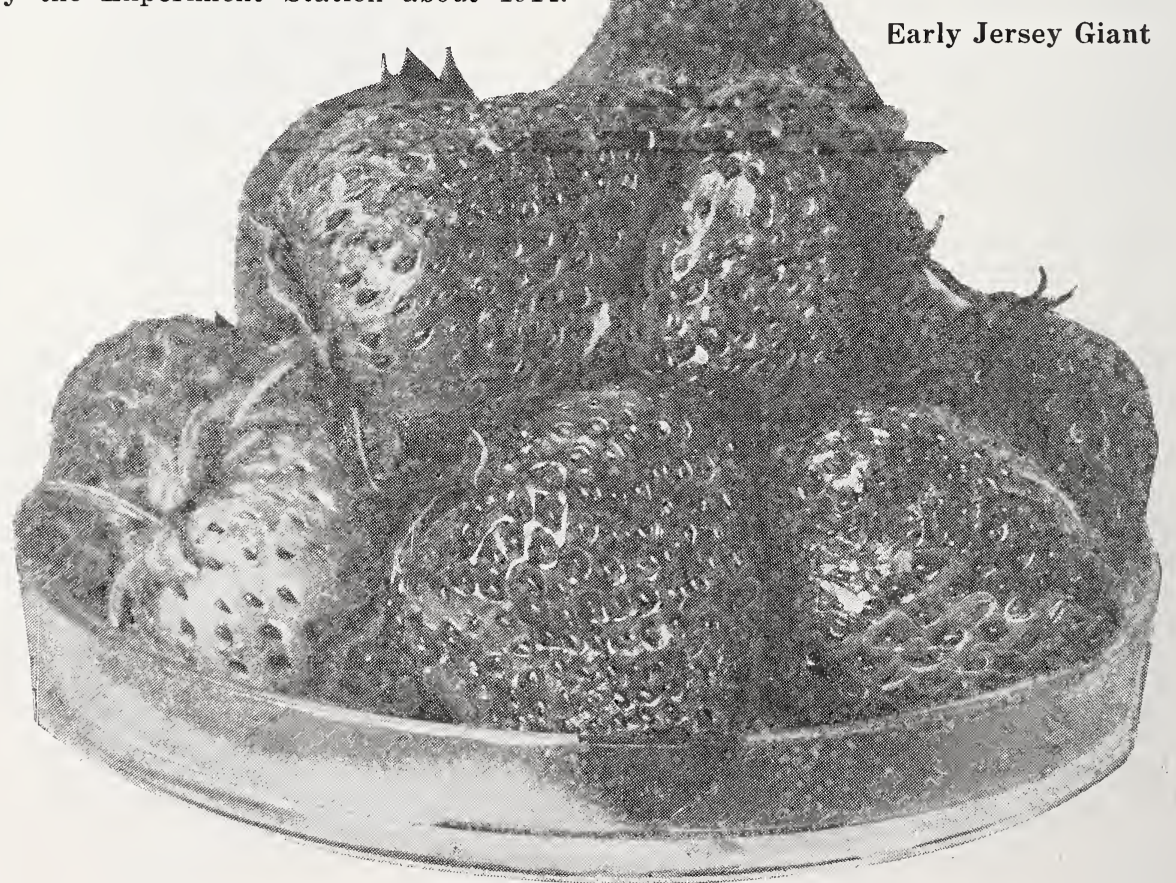




\section{Medium Varieties}

SENATOR DUNLAP (Per.)-This is by far the leading Strawberry throughout the United States. The demand for this wonderful berry has steadily increased since its introduction, and there is a shortage of plants every season. It does well everywhere and produces enormous crops of fine fruit regularly. Senator Dunlap has a perfect blossom, is hardy, productive, and seems able to produce a good crop under any circumstances. A crop failure with the Dunlap is unknown. Senator Dunlap is a very heavy bearer of large, good shaped fruit of the highest quality, and will bring the top market price anywhere. The flower is simply delicious. For preserving it is simply fine, and it makes a rich dark red syrup, very pleasing in appearance and flavor. It is a first-class shipper and retains its brightness long after being picked. It always looks well on the market, and sells quickly at fancy prices. The best proof that we have to offer of the universal popularity of this variety is the fact that our customers in every state of the Union are ordering Dunlap in larger quantities. The demand has never been supplied, and we urge our customers to order their requirements early. We have a fine supply and they will please you.

DR BURRILL (Per.)-Berries are very large and uniform in size and shape. Most of you know what Senator Dunlap is and what loads of nice berries they are producing everywhere. Dr. Burrill is a better berry in every way, produces more berries, bigger berries and berries of better quality. This is a big statement, but Dr. Burrill has proven its value on the grounds of the originator and on the farms of the introducers. This great

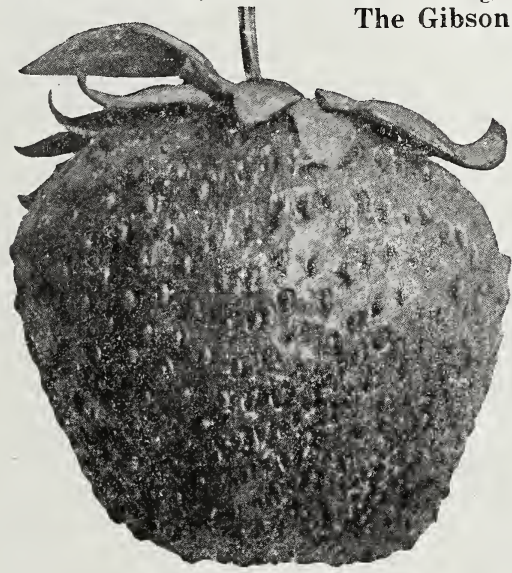

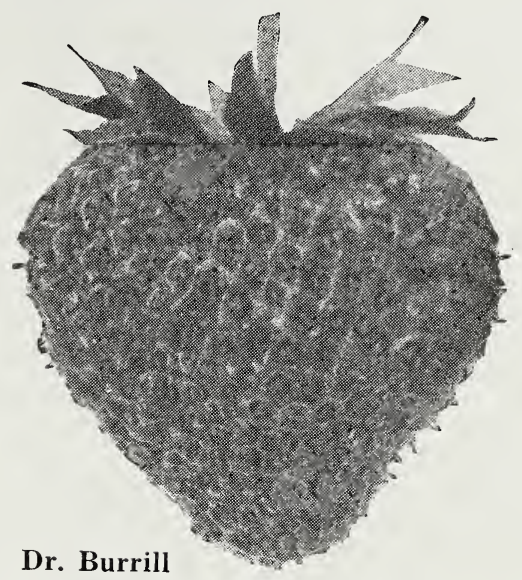

new variety is a strong fertilizer, and its season of blossoming and fruiting is extra long. It ripens in mid-season. Dr. Burrill stands the drought best of all varieties owing to its wonderful root system. Foliage is large, of a beautiful dark green and very hardy and healthy. With its extra long, strong roots, heavy crowns and healthy foliage, it is able to produce its wonderful crop of fruit every season. Berries are very dark red in color, and are of the very best quality.

THE FAMOUS GIBSON (Perfect)-Gibson commences to bear with Senator Dunlap, etc., but owing to its wonderful productiveness it continues until quite late, so we class it with our medium late varieties. It is a very strong grower, with long roots that withstand dry weather, and has plenty of dark green foliage to protect its enormous crop of fruit from the direct rays of the sun. The vines are simply loaded with berries. You will hardly understand how the plants can produce such quantities of fruit. Berry is extra large. One of our very largest strawberries. A beautiful dark, glossy-red. The flesh of the berry is red clear through. Calyx is bright green, adding greatly to its beauty and market value. The flavor is as fine as can be found in any strawberry; a perfect table and canning berry, and owing to its tough skin it is a very fine shipper. Nearly round and regular. A berry which sells itself on any market. We have again grown a nice stock of extra strong Gibson plants and we hope every one of our customers will include some plants of this profitable variety in their order this year. 
PROLIFIC (Per.)-We are very enthusiastic over the Prolific after fruiting it several seasons and consider it one of our best sorts. Plants very numerous, unusually productive. Has a record of yielding as high as 14,502 quarts per acre. Blooms and ripens in midseason, picks easily. Fruit very large to above medium retains size well as season advances, roundish cone to blunt wedge, rather light in color, but nevertheless an attractive bright scarlet. On account of its vigor, the great productiveness of its plants, and the attractiveness of the large, well-colored berries, this variety gives promise of taking front rank among standard commercial strawberries.

BUSTER (Imperfect)-Another variety that is hardly new. This is an excellent plant maker, filling the row with strong healthy plants. The foliage is very abundant, glossy, dark green. The fruit at first ranges from medium to very large but diminishes in size until during the latter part of the season it is small, and yet the small berries are perfect and hence the size is not nearly so objectionable as though they were "nubs." The fruit is rather light in color but the few large sunken seeds made it very attractice looking. This variety easily outyielded all others, yielding nearly double the quarts of its nearest competitor. Season early to midseason. The above description as given by the Ohio Experiment Station, Bulletin 236. Price $\$ 1.00$ per $25 ; \$ 2.50$ per $100 ; \$ 20.00$ per 1,000 ; 500 at 1,000 rate.

\section{Late Varieties}

PAUL JONES (Imperfect)-One of the most productive berries we have ever seen. A vigorous grower, making plenty of plants for a good fruiting bed. This year, on high, sandy land, the plants produced for us over 5,000 quarts per acre and if it had all been as good as some of the more moist spots, we believe they would have produced 8,000 to 10,000 quarts, without any manure or fertilizer being applied, either at planting time, or in the spring before fruiting. The berries are rather long and conical in shape, resembling Haverland; but they are somewhat darker in color and more at-

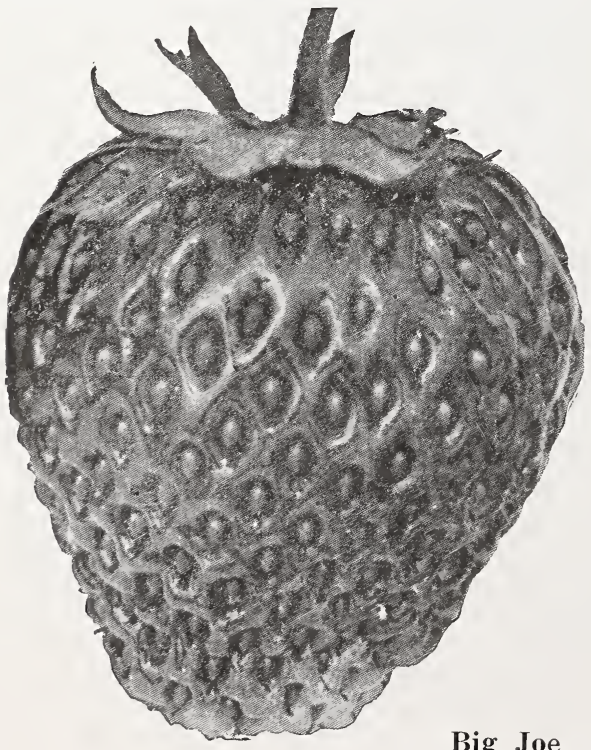

tractive in appearance. They are above medium in size, ripen evenly all over, of good quality and a good shipper. We use this variety very largely in our fruiting patches. They will grow almost anywhere, and they certainly do produce the fruit. The blossoms are imperfect and should be planted with Big Joe or some other perfect flowering variety of its season. Price $\$ 1.00$ per $25 ; \$ 2.50$ per $100 ; \$ 20.00$ per 1,000 .

BIG JOE (Perfect)-One of the most popular shipping berries on nearly all large markets. It is a strong grower, making plenty of plants for a good fruiting bed. The berries are large, bright red and have large, light green caps, which makes the berries very attractive, and adds to the selling price. The quality is good and the berries are quite firm. It is a good shipper and equally good for fancy local market purposes. One of the most productive. One of the best to plant with heavy-bearing imperfect flowering varieties like Sample. Price $\$ 1.00$ per $25 ; \$ 2.50$ per $100 ; \$ 20.00$ per 1,000 .

SAMPLE (Imp.) -A valuable, large, late variety. Sample scored such a marked success in many places that no progressive grower can afford not to plant some of it. The successful man is he who tests all really promising varieties and in that way quickly finds those suited to his own soil, climate, etc. Michigan Horticultural Experiment Station says: "Sample has proven itself to be a very valuable sort. It is hardy and productive of choice, attractive berries. It has large, healthy, foliage, and stout fruit stalks. With 


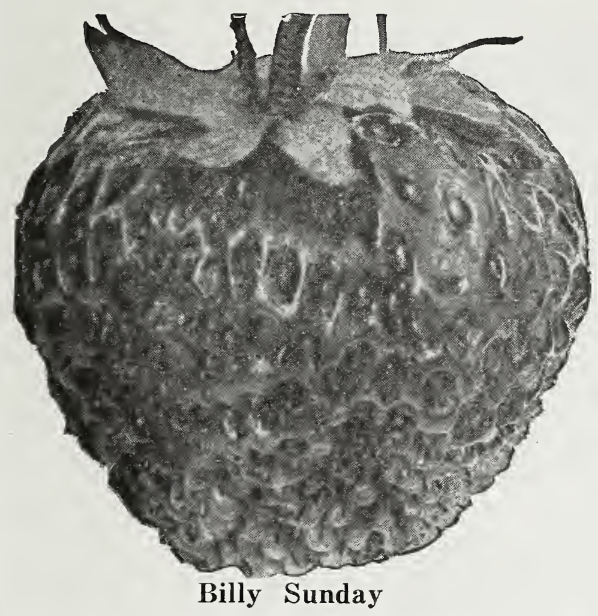

strong soil and good culture it is one of the most promising kinds for general purpose planting."

BILLY SUNDAY (Per.) - An Ohio grower says: "I have been growing Strawberries for fifteen years and have fruited nearly all standard varieties, but haven't found any that will take the place of Billy Sunday. The plants are hardy, great crown-makers, tall, dark green foliage, long heavy fruit-stalks, making berries easily gathered. The fruit is large, glossy red, slightly wedge-shaped, uniform in shape and size, and has a delicious sweet flavor.

FORD (Perfect)-Ford is a mid-season to late. An ideal and universal variety. We offered Ford for the first time about six years ago, and stated that it would become as well known in a few years as its namesake, the Ford Car. We have not lost our bet. The Ford is almost a second Premier. About the only difference is the Ford is a week later in ripen- ing. Ford is exceedingly productive of large, bright red berries, red to center, and with very best flavor. Is firm enough to be a good shipper and to be grown anywhere. A strong, healthy plant maker, large blossoms which are very rich with pollen. In the Ford we have a variety that will be very hard to beat. Has now been on the market four years. We have not boosted it in our Catalogs as its merit demanded. The Ford has gained in popularity year after year, until today we are selling as many Ford plants as any other variety on the list. And the remark that we made in our announcement six years ago that the Berry would become as well known as the "Ford Flivver" in whose honor it was named we still hold good. We have received more good reports from the State Experiment Stations on this variety than any other variety we have ever listed.

We could print a book three times the size of this and not give half the testimonials we have received regarding this berry. We conclude by saying that the Ford is truly an ideal berry, easy to grow, good in size productiveness, and quality delicious red all over through and through. Blooms late making it a sure cropper, long roots, makes it a great drought resister, has never missed a crop from Maine to California. Place orders carly and save disappointment, for no matter where you are situated you can not afford to be without a Ford.

A Penna. grower writes: "I thought Chesapeake would never be surpassed for quality, but Ford goes them one better. Plants are so much more hardy and productive. Will discontinue Chesapeake and grow only Ford."

We also have discontinued Chesapeake for the same reason.

Price: $\$ 1.00$ per $25 ; \$ 2.50$ per 100 ; $\$ 20.00$ per 1,000 . 500 at 1,000 rate.

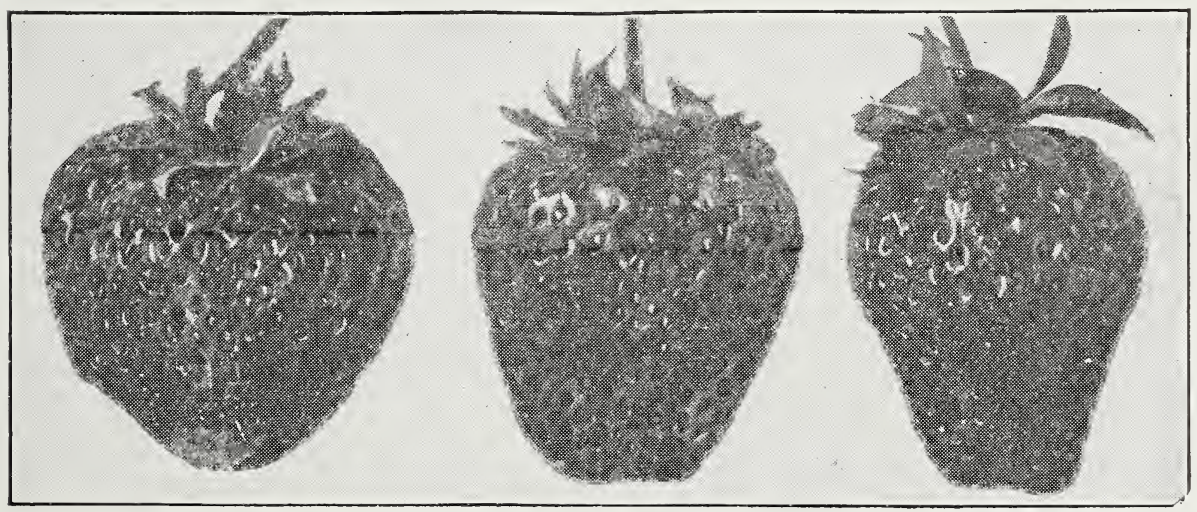




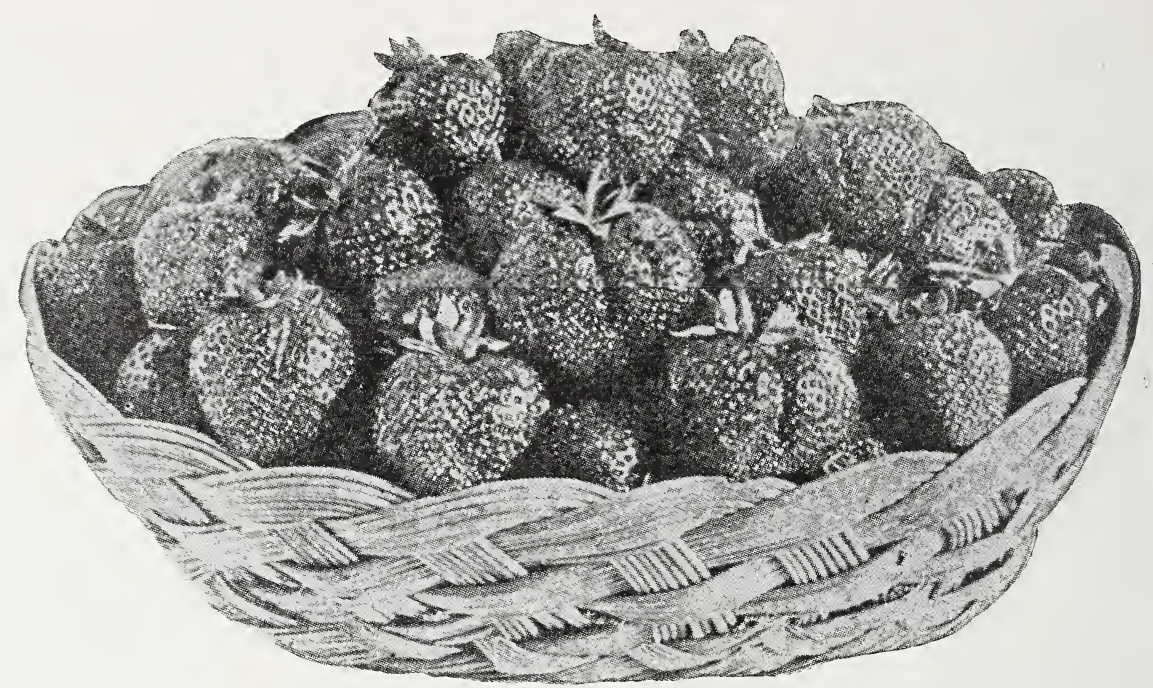

Kellogg's Prize

\section{Very Late Varieties}

KELLOGG'S PRIZE (Imperfect)-We have grown this valuable variety for several seasons and find it to be all the introducers claim. "Kellogg's Prize is unquestionably the heaviest fruiting late variety yet introduced. The berries of Kellogg's Prize are not only borne in large quantities, but are very large and most beautiful, and their quality is ideal in every respect. It has no preference for any particular soil or climate, but produces its customary load of berries wherever it is grown. It is a very strnog growing pistillate or female variety, makes a tall foliage which protects the blossoms from frosts and affords shade for the berries. In every way it is a late variety that will win the admiration of everyone who grows it, and we are confident that no variety will make the grower a larger profit than Kellogg's Prize. Growers who started with only a few plants have increased their acreage every year and many now are using Kellogg's Prize as their leading late variety. We are confident that we could do you no greater favor than to urge you to order Kellogg's Prize, whether you grow berries for home use or market." Please note these qualifications: The vines are simply loaded with berries of a beautiful dark glossy red. One of the largest berries we have ever grown; round and regular; very beautiful Fruit stems are plenty, strong and upright. We have an excellent stock of these plants and urge you to plant them.
LUPTON (Perfect.)-The Lupton is one of the latest additions to our already long list of late varieties. We have heard so much talk of it for the past two years we bought from the Originator a good supply of plants last spring, and now have a fine stock of true to name plants. We describe it as follows: A strong grower, plants very tall and stalky makes plants freely and can be distinguished from all other varieties for a great distance. The fruit is extra large and the firmest berry we have ever seen. Color a rich shiny red, no green tips, color all over, in examining this berry the past spring in crate after crate at the shipping station we failed to find a single misshaped berry. Such grand varieties as Big Joe, Kellogg's Prize, Big Late, Chesapeake, Sample, etc., have got to get a hustle on now or lose their standing.

Is truly a show berry and one of the very best sellers on the market. We have never seen a berry that makes a better show when crated up for shipment; has a large showy calyx that sets off the bright red berry. Lupton is sure to be a winner and we advise all commercial growers to try it. One of the largest and most handsome berries we have ever seen. The plant is a vigorous grower and produces strong, healthy foliage. They are very productive, and as stated above, the berries are beautiful-they are uniformly large, bright red in color, with a large green cap which makes them doubly attractive. The quality is poor, but 
the berries are firm and will carry as well as any variety we have ever seen. On the large markets the appearance of berries is more important than qualitythis being true, we believe the Lupton, by reason of its large size, handsome appearance and excellent shipping qualities, is destined to be one of the best money-making strawberries on our list. It is sold at the station for the highest price of any berries we had last year. Price: $\$ 1.00$ per $25 ; \$ 2.50$ per $100 ; \$ 20.00$ per 1,000 . 500 or more at 1,000 rate.

AROMA (Perfect)-This is our best and most profitable late strawberry. Extra big profits in berries are always made by getting your fruit on the market when the demand is best.

For the big money in berry growing we recommend very early or very late varieties as they mature their crops either before or after the heavy picking season.

Aroma is among the latest strawberries grown and one of the best varieties of strawberries.

They produce an immense amount of extra large, fancy looking berries and the quality and market value is the very highest.

Every strawberry grower should plant Aroma to lengthen his fruiting season and make him more money. Many big growers especially in the Southwest plant large fields to Aroma alone for distant markets as it is one of the very best shipping varieties grown.

More Aroma are planted in commercial districts than all other varieties put to-

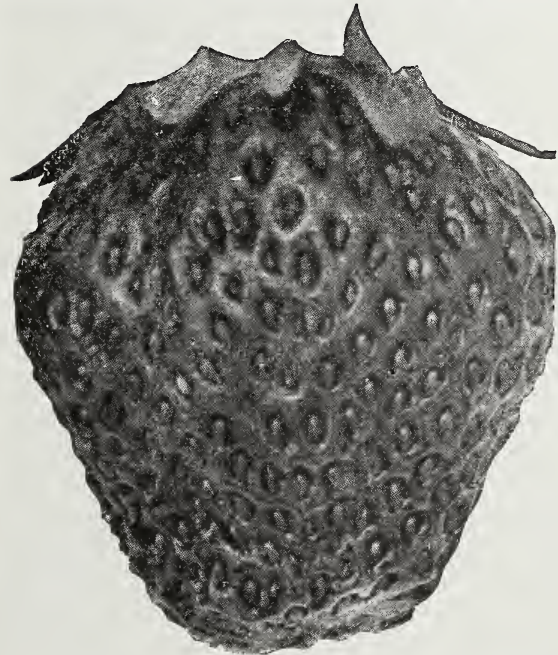

Lupton Late

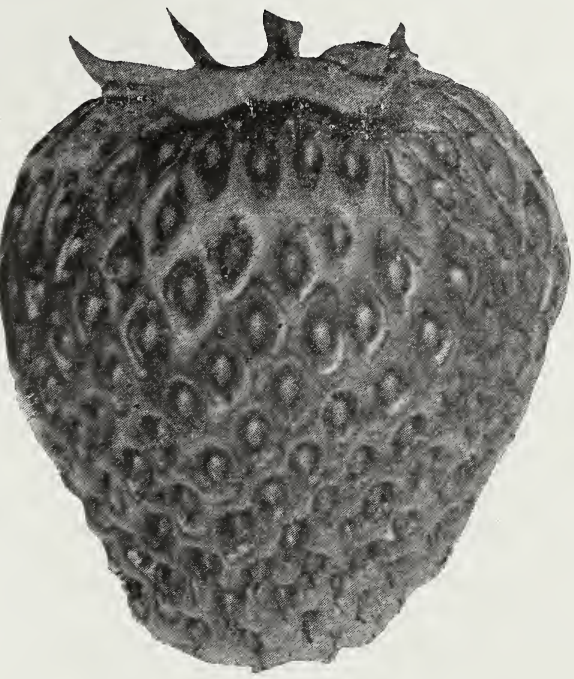

Aroma

gether. It is a very remarkable berry, very large and firm and of the finest color. The berry holds up exceedingly well in the box. The plant is large and stocky. The foliage healthy and never makes plants freely like Dunlap or some other varieties. Hence the reason we cannot sell the plants of Aroma as cheaply as we sell Dunlap. The fact is that many good varieties of strawberries have been discarded because the public will not pay the price that will enable the grower to grow them at a profit. The buying public seems to think that one variety should be sold as cheaply as another. It cannot be done. Hence the reason that the nurserymen discard many good varieties. We have grown many varieties at a loss but as soon as an opportunity offered, we dropped them. In our own country the Aroma succeeds best on hill land. Just ordinarily fertile. It is always a sure bearer and the berries always top the market. We should say to everyone to plant some Aroma. If it succeeds with you plant some more of them. Especially if you are growing berries for the market. We will guarantee the fruit of Aroma to please all who give it a fair trial. It cannot well be beaten for quantity of fruit produced or in quality of fruit. Plants show no weakness of any kind. The demand for Aroma plants has exceeded the supply every year for the past ten years. We have grown an extra large stock of fine Aroma plants but we advise you to place your order early to be sure of getting them. Price: $\$ 1.00$ per $25 ; \$ 2.00$ per $100 ; \$ 15.00$ per 1,000 . 


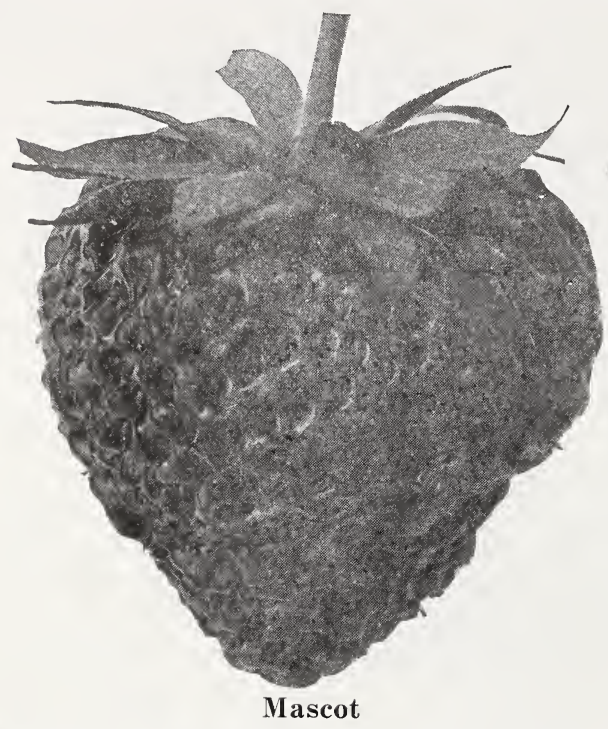

GANDY (Per.) - This is one of the most reliable, large, late berries that is grown. It is one of the old standard varieties that you can depend upon. It is a strong grower and a good plant-maker. The large, handsome, appearance of the fruit always commands for it a large price in market. The fruit always grows large and is one of the best shipping varieties known. In some localities the Gandy is not so productive as some varieties, but the fact that it ripens late and is of a hardy nature indicates that it will do well in any soil where other berries grow. You can't afford to be without Gandy, whether for home or market.

MASCOT (Perfect)-Virginia origin; introduced in 1908. Berry large, irregular globose-conic to short wedg? shaped, medium red color with red flesh, firm, mild sub-acid, quality good; season late to very late. The Mascot has been widely tested in New Jersey, Delaware and Maryland, and is now being grown extensively in some parts of those states. It is liked because it is later in season than the Gandy and is very productive, with very large attractive berries of excellent quality. In New Jersey it does not have the white or green tip, which often detracts from the appearance of the Gandy, and its quality is considered better. It is recommended for testing where the Gandy succeeds. Price: $\$ 1.00$ per $25 ; \$ 2.50$ per $100 ; \$ 20.00$ per 1,000 .

\begin{tabular}{|}
\hline NO'TICE \\
If you are interested in orna- \\
mental trees and other fruits be- \\
sides strawberries, send for our \\
beautiful illustrated Catalogue de- \\
scribing hundreds of varieties of \\
trees grown and offered for sale by \\
us at very low prices-Mailed Free \\
to all applicants.
\end{tabular}

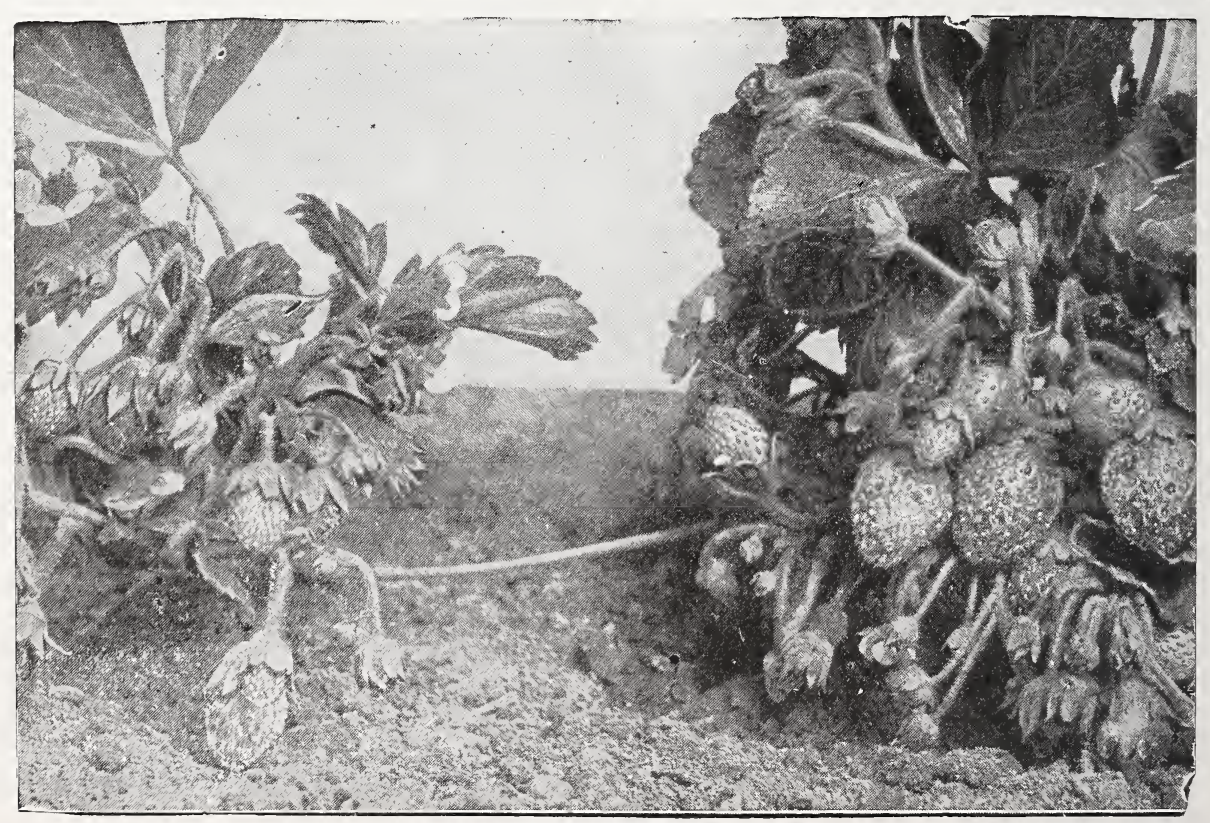




\section{Special Varieties}

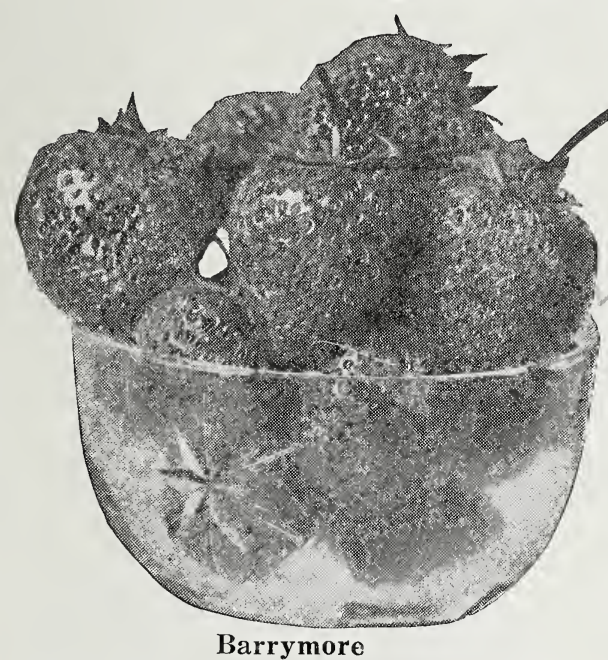

The four varieties following, the Barrymore, Good Luck, Bushel Basket and Amanda, are our latest acquisitions and we offer only a limited number of plants this season. The prices of these varieties are necessarily higher than the preceding standard varieties, but all of them are very strongly recommended by the N. Y. Experiment Station for general trial throughout the country. We hope to have a number of our customers try them out. We believe them to be far and away ahead of any varieties heretofore produced and offered. The descriptions given are those published by the N. Y. Experiment Station but very much abbreviated. We will offer plants of all of them at the uniform price-25 plants for $\$ 2.00 ; \$ 5.00$ per 100 .

BARRYMORE (Per.)-The N. Y. Horticulture Experiment Station reports a yield of 12,500 quarts per acre by this variety. Combines unusual qualities, attractive color, large size, desirable shape, with flavor and quality superior to most. Its late blooming habit is a valuable asset in localities subject to spring frosts. Produces a large number of runners. An ideal variety for early midseason. Strongly recommended for trial by the N. Y. Experiment Station. Price: $\$ 2.00$ per 25 plants; $\$ 5.00$ per 100 .

GOOD LUCK (Semi-perfect to perfect) -The fruit is large and ripens a few days ahead of Gandy. In shape it is conical to wedge shape. The plant is a strong grower. Recommended by N. Y.
Experiment Station. Ranking among the best late strawberries on the station's grounds. Surpassing all of them in yield and proved to be one of the best shippers. Plants are about the least susceptible of any sort to leaf-spot. The quality is particularly good, having a most distinctive flavor. Frice $\$ 2,00$ per 25 plants; $\$ 5.00$ per 100 .

BUSHEL BASKET (Per.)-This variety has had an unusual name. We secured some plants in 1920 from the introducer, Mr. Katkamier, of N. Y. State. We have seen no fruit but the growth of the plants fully live up to the description and name which he gives. Is without doubt the largest plant we have ever grown, and we are looking forward to see some fine large berries. The introducer offers $\$ 1,000$ in Gold for 100 plants of any new strawberry that has the money making qualities of the Bushel Basket Strawberry. This is a pretty good offer and one we should all go after. We advise testing this variety at once, and that you place order at once. Price $\$ 2.00$ per 25 ; $\$ 5.00$ per 100 .

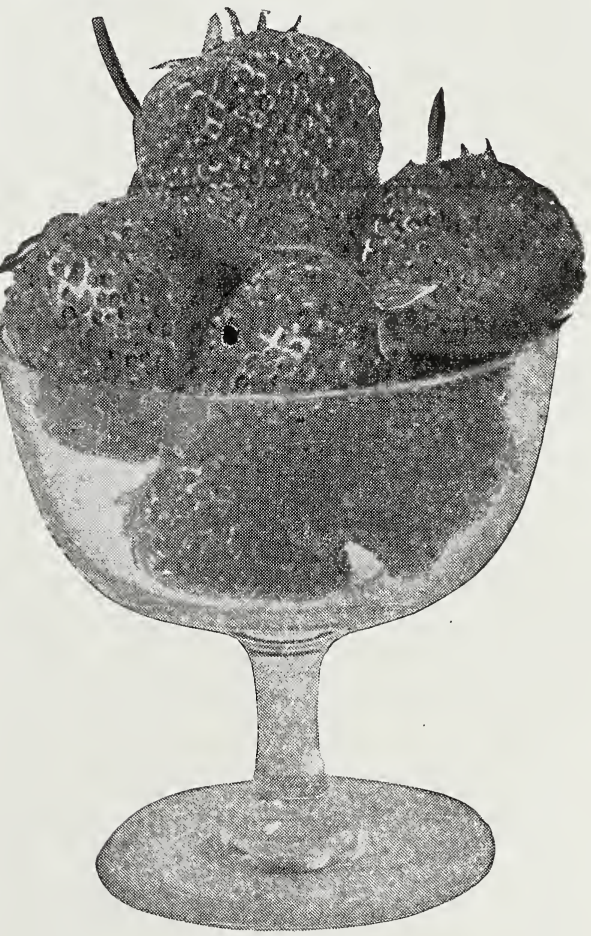

Good Luck 


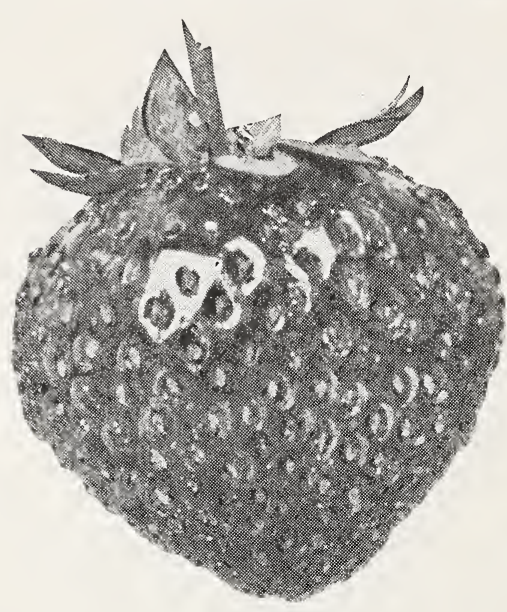

Amanda

AMANDA (Perfect)-The largest berry we have ever seen. Plants are large, vigorous and healthy. Blossoms are perfect. The fruit is dark red in color, somewhat irregular in shape and of good quality. It is very productive. Mr. Fred Harvey of Virginia says: "I have tried a great many strawberries, but have none ever approached Amanda in size or productiveness, and no one that I know, can excell you in either plants or packing. One of our newest.

The following description of Amanda is published in a bulletin issued by the N. Y. Experimental Station, entitled "New and Noteworthy Fruits:"

"Amanda has been under observation at this Station for several years, having first fruited in 1908. Every year the fruit has attracted attention because of its desirable qualities. We now have no hesitation in recommending Amanda for trial, both for home use and for commercial purposes. Sufficient room must be given both for rows and plants as the runners are produced in great numbers. The plants, vigorous and rank, among the most productive of over one hundred varieties. The blossoms are perfect and open in mid-season or later, usually after danger from late spring frost is past. The great asset of Amanda is the fruit. The berries ripen in mid-season, are large and hold up remarkably well throughout the ripening season. The color varies from light to dark scarlet depending on the stage of maturity and is always glossy and attractive. In shape, the berries are usually a distinct blunt-wedge although roundish-conic forms may be found among them. The flesh is firm enough to stand the wear and tear of distant shipments and its color is good to the very center. There is enough acidity of flavor to give sprightliness which, combined with other characters, makes the variety rank high in quality. Amanda is well worthy of trial for home but more particularly so for market." Price $\$ 2.00$ per $25 ; \$ 5.00$ per 100.

We have been in the plant business in Lafayette since the year 1884. We are still at it. Our experience should count. Results are what you want. We know what varieties should produce you best results. We allow no varieties on our list that fail to measure up to the highest possible standard.

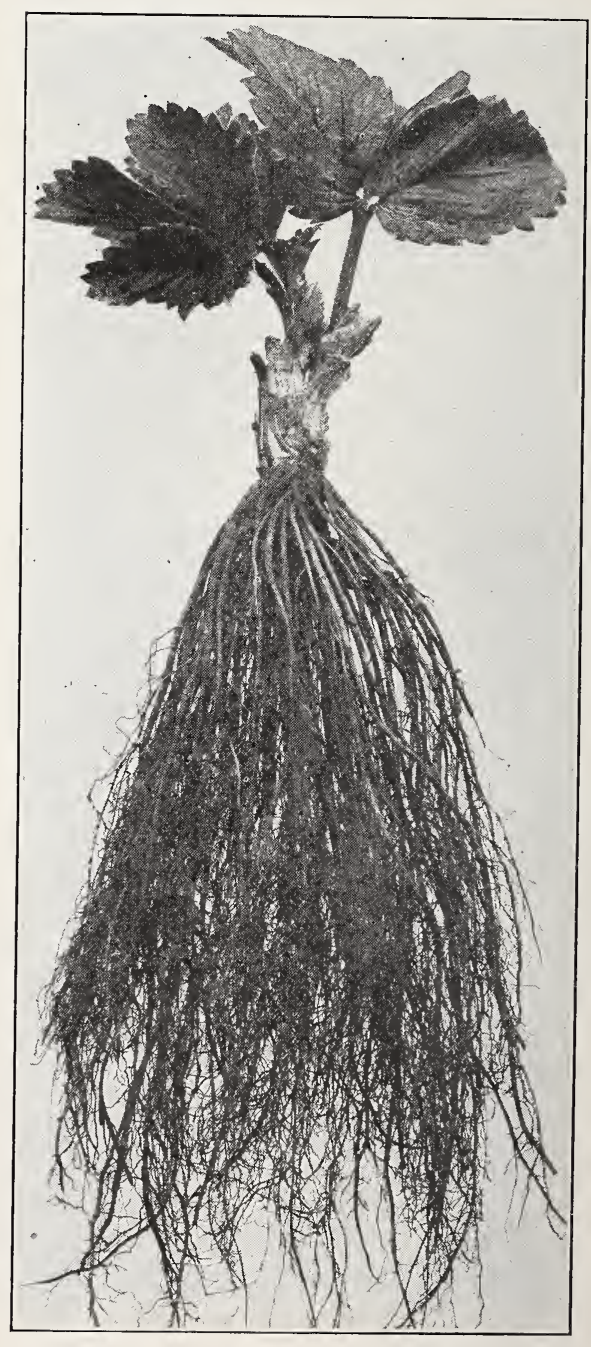


The high cost of living is the most dangerous thing in the world today. There is only one way to make a permanent reduction in the cost of living and that is to increase production. We cannot very well make our own clothes, but we can grow fruit in our back yards and gardens.

We ask our friends to consider becoming producers by at least growing those Small Fruits needed for their household consumption. Why pay 50c per quart for Strawberries when you can grow them yourself? With a few plants in your garden it is possible to grow all the strawberries you need.

Cut your high cost of living by becoming a producer. Fruit growers realized $\$ 300$ to $\$ 700$ per acre from Small Fruits during the past season, and as prices are more than likely to remain high for some years to come, we consider the Small Fruit Business a very promising one for you to enter.

\section{WHY EVERYBODY SHOULD PLANT THE STRAWBERRY}

BECAUSE IT IS ONE OF THE VERY BEST OF FRUITS AND MOST UNI-

VERSALLY POPULAR-One of the wholesomest-nothing being more conducive to health in spring than the liberal eating of fresh, thoroughly ripe, home-grown strawberries.

THE MOST USEFUL as an article of table diet, after the apple, and the most generally consumed. Everybody eats strawberries twice a day that can get them.

THE MOST PRODUCTIVE-In no fruit will a given plot of ground give as enormous returns under high culture as in strawberries.

THE MOST PROFITABLE-In no fruit that grows can, under good management, an acre of land be made to pay as large a profit. Everybody wants strawberries. Most people have to buy them. Money can be made on first class strawberries anywhere. In city, town, village, or even in a country neighborhood, buyers for this exceedingly popular fruit can always be found.

neighborhood, buyers for this exceedingly popular fruit can always be found.

THE EASIEST TO GROW-Anybody under almost any conceivable conditions can grow the strawberry with some measure of success, therefore nothing responds more fully to high culture.

THE SUREST, being one of the few things grown that never fails entirely. Nine years out of ten it yields well under even the most unfavorable of conditions.

IT SUCCEEDS EVERYWHERE, adapting itself to a greater variety of soil and climate than any other fruit, or even plant, that grows. No matter where you live, no matter whether your soil is rich or poor, clay or sand, wet or dry, flat, hilly, stony or what not, there are varieties of the strawberry that will succeed with you.

IT IS THE QUICKEST-No other fruit gives as quick returns. Set in the fall it will, with a fair showing, bear the following spring a good crop of large, fine, early berries, and very large crops for several succeeding springs.

IT IS THE EARLIEST-The strawberry is the advanced guard of all the grand host of fruits, ripening in the very forefront of spring, when fruit is craved and needed most. 
We can't afford anything but the best, Can You?

\section{THE LAFAYETTE NURSERIES WEST LAFAYETTE, INDIANA}

Grounds adjoining the United States Experiment Station and Purdue University 